\title{
Quality Monitoring Research of Small Scale Resistance Spot Welding Based on Voltage Signal
}

\author{
Dawei ZHAO, ${ }^{1 / *}$ Yuanxun WANG, ${ }^{1)}$ Zongguo LIN $^{21}$ and Suning SHENG ${ }^{2)}$ \\ 1) Department of Mechanics, School of Civil Engineering and Mechanics, Huazhong University of Science and Technology, \\ Wuhan, 430074 China. $\quad$ 2) Grand Master Trading Limited, Miyachi Unitek Corporation, Nanjing, 211100 China.
}

(Received on August 30, 2012; accepted on October 17, 2012)

\begin{abstract}
With the rapid development of microelectromechanical systems, small scale resistance spot welding (SSRSW) is ever-increasing used in electronic and medical devices. Whereas there is limited research work dealing with quality control of SSRSW. This paper investigated a real-time and in-situ SSRSW quality monitoring method by means of taking the voltage as the monitoring signature. It was obtained through clipping two leads onto the electrodes during SSRSW. As the linear DC and the high frequency (HF) resistance welding power supplies were the common equipments in SSRSW and constant current mode was used in this study, the variation of voltage with time indicated the conditions of the welding process which issued in the final weld quality. Utilizing four factors extracted from the voltage curve an artificial intelligence algorithm to estimate the weld quality was proposed. The maximum average forecast error of the trained network is about $0.15 \mathrm{~mm}$, showing that the voltage curve is a reliable quality monitoring signature of SSRSW. The most prominent advantage of this method is that weld quality can be perfectly estimated with only two sensor clips compared with other methods reported for normal scale or large scale resistance spot welding (LSRSW).
\end{abstract}

KEY WORDS: small scale resistance spot welding; voltage curve quality monitoring; artificial neural network.

\section{Introduction}

As shown in Fig. 1, during resistance spot welding (RSW), two electrodes contact an overlap of two sheet metals and very high dc or ac current is passed for a short period of time. The resistance between two heads of electrodes offers to the flow of electric current produces heat. According to the joule law, the heat produced causes the interfaces to melt and form a solid joint. The electrodes are usually water-cooled to prevent the welding plate from sticking onto the electrodes.

With the rapid development of microelectromechanical systems, small scale resistance spot welding (SSRSW) is commonly used in electronic and medical devices. Compared with normal scale or large scale RSW (LSRSW), SSRSW deals with relatively thin sheet metal (sheet metal less than $0.2-0.5 \mathrm{~mm}) .{ }^{1,2)} \mathrm{SSRSW}$ is distinct from LSRSW in many respects, ${ }^{3,4)}$ see Table 1. Electrode sticking, expulsion, and non-repeatable welding may occur on condition of simply reducing welding parameters. ${ }^{5-7)}$ There have been some studies on SSRSW. Zhou et al. ${ }^{8)}$ investigated the weldability of thin sheet aluminum, brass, and copper in SSRSW. Ely and Zhou ${ }^{9)}$ studied the weldability of Kovar, steel, and nickel. Shinji Fukumoto ${ }^{10)}$ investigated the weldability of austenitic stainless steel. W. Tan ${ }^{11)}$ expounded the dynamic resis-

\footnotetext{
* Corresponding author: E-mail: 641129789@qq.com

DOI: http://dx.doi.org/10.2355/isijinternational.53.240
}

tance during small scale resistance spot welding (SSRSW) of $\mathrm{Ni}$ sheets and pointed out that the dynamic resistance curve could be divided into six stages. However, little work is available dealing with quality control of SSRSW. Thus it is necessary to investigate an effective method to monitor the quality of SSRSW.

There are various non-destructive testing methods to monitor weld quality or welding process of LSRSW. Ultrasonic testing can detect the unusual small dimension, loose

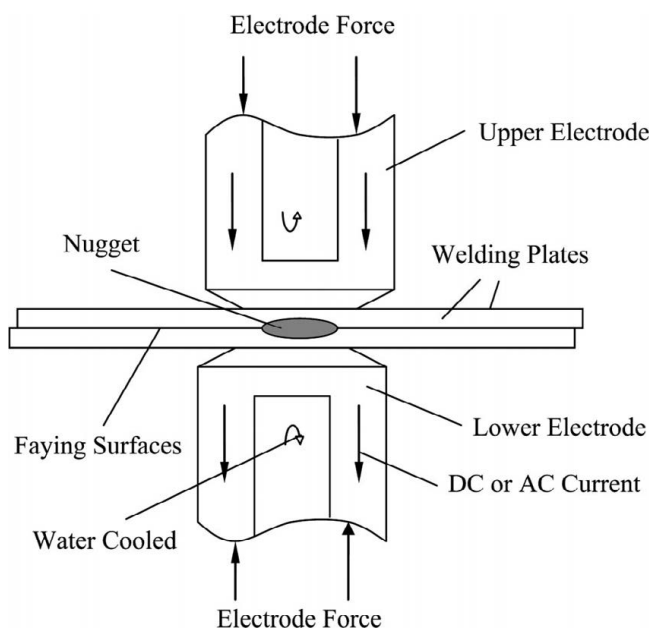

Fig. 1. A schematic drawing of a spot welding system. The figure displays the basic principle of resistance spot welding. 
Table 1. Differences between SSRSW and LSRSW. The table displays differences between SSRSW and LSRSW in many aspects.

\begin{tabular}{|c|c|c|}
\hline & SSRSW & LSRSW \\
\hline Sheet thickness & $<0.5 \mathrm{~mm}$ & $>0.5 \mathrm{~mm}$ \\
\hline Electrode force & $<90-450 \mathrm{~N}$ & $>2200-4500 \mathrm{~N}$ \\
\hline Electrode pressure & $<30-60 \mathrm{Mpa}$ & $>120-240 \mathrm{Mpa}$ \\
\hline Welding current & $<2-4 \mathrm{kA}$ & $>4-10 \mathrm{kA}$ \\
\hline Welding time & several milliseconds & Often less than a second \\
\hline Spot welding machine & Desktop type & Verticle type \\
\hline Power supply & Direct current (DC) & $\begin{array}{l}\text { alternating current (AC) } \\
\text { capacitive discharge (CD) }\end{array}$ \\
\hline Electrode cooling & Air cooling & Water cooling \\
\hline Electrode sticking & More likely to occur & Sometimes occur \\
\hline Nugget diameter & $\begin{array}{c}1 / 3-1 \text { of electrode } \\
\text { diameter }\end{array}$ & $\begin{array}{c}1 / 2-1 \text { of electrode } \\
\text { diameter }\end{array}$ \\
\hline Materials & $\begin{array}{l}\text { Mainly non-ferrous } \\
\text { metals, such as } \mathrm{Cu}, \\
\text { Kovar, } \mathrm{Ni}, \mathrm{Ti} \text { and silver } \\
\text { (plated and bare) }\end{array}$ & $\begin{array}{c}\text { Mainly steels, such as } \\
\text { carbon steel and stainless } \\
\text { steel (plated and bare), } \\
\text { some Al alloys }\end{array}$ \\
\hline Plating material & $\mathrm{Au}, \mathrm{Ag}, \mathrm{Ni}, \mathrm{Sn}$, etc & $\mathrm{Zn}, \mathrm{Sn}$, etc \\
\hline Typical applications & $\begin{array}{l}\text { Medical device and } \\
\text { electronic components }\end{array}$ & $\begin{array}{l}\text { Automotive body, } \\
\text { electrical appliances }\end{array}$ \\
\hline
\end{tabular}

weld, and porosity of a weld nugget. ${ }^{12-14)}$ However, it is only applicable to off-line use because of the high cost, demanding operator skill, high requirements on the surfaces of sheet metals, and relatively complicated inspection system installation. Keiji Tsukada developed a magnetic flux leakage (MFL) system using a magnetoresistive (MR) sensor for nondestructive spot-weld inspection. ${ }^{15)}$ Whereas, it only could be applied to the ferromagnetic materials; metals to be welded in SSRSW are mostly nonferrous. ${ }^{16)}$ Measurement of the electrode displacement is another non-destructive method. ${ }^{17,18)}$ It is a real-time and in-situ RSW quality monitoring method, but its application is limited in the field of SSRSW. Because much small workpieces lead electrode displacement very difficult to measure, monitor and control. Ling ${ }^{19)}$ focused on the use of input impedance of a manufacturing system as a signature for monitoring the manufacturing processes. By recognizing the pattern of the real part by an artificial neural network, it is demonstrated that the input impedance can be used as a quality monitoring signature for characterizing resistance spot welding. However, the physical meaning of input impedance changes during a welding process is unknown and calculating the input impedance steps is complex and difficult to understand. J. Wen ${ }^{20)}$ explored the effects of various process conditions in spot welded stain-less steel on quality by using dynamic resistance and showed that dynamic resistance responded well to the variations of process conditions and can serve as an important indicator of weld quality. Nevertheless, as the dynamic resistance was measured by dividing the instant voltage and current at its peak value within every half cycle, the dynamic resistance was highly discontinuous and not precise.

During resistance spot welding, the materials to be welded undergoes thermal expansion, yielding, melting, cooling and solidification; its electric conductivity and the whole loop impedance change constantly, the voltage between two electrodes also changes, and has certain law. So we can use voltage as a spot welding quality monitoring signature. Archer ${ }^{21)}$ built a feedback control to regulate the welding current based on the voltage measured. When the voltage measured was higher/lower than a command value, the current was lowered/raised to change the weld size. A similar monitor system based on voltage integral was obtained by Williams. ${ }^{22)}$ The voltage integral over welding time was used as a parameter to monitor the nugget diameter. This monitor system developed a feedback control combined the monitor with current stepwise adjust algorithm. The current was raised when the monitor indicated a smaller weld size; and it was lowered when the monitor indicated a bigger weld size. The systems was proved to be a good monitor system worked well with uncoated mild steel, various coated steels, and aluminum alloys.

As for the quality monitoring of SSRSW, the voltage is difficult to measure, monitor and control due to its small changes in amplitude. Fortunately the linear DC or the HF resistance welding power supply provides more welding consistency and less noise compared to traditional direct energy (AC) or capacitive discharge (CD) technologies used in LSRSW.

\section{Experimental Study}

The voltage was monitored during the welding cycles using a 12-bit computer data acquisition (DAQ) system with $50 \mathrm{kHz}$ sampling frequency per channel. Figure 2 shows the implementation of sensors for the welding process. Two leads were clipped onto each of the electrode to measure the voltage between them. The sensor leads were shielded twisted pairs to reduce the electromagnetic contamination to the signals. A two channel Butterworth low pass filter was used for anti-aliasing purpose during the analog signals sampling. At last the signals were evaluated by a Matlab program.

In the presented study, the material used was TC2 titanium alloy with a thickness of $0.4 \mathrm{~mm}$. The alloy has satisfactory plastic, good weldability and its chemical compositions are shown in Table 2. The TC2 Ti sheets were cut in the dimension of $100 \times 30 \times 0.4 \mathrm{~mm}$, installed as lapping joints, as shown in Fig. 3.

When the temperature is higher than $550^{\circ} \mathrm{C}$ titanium and its alloy easily produce chemical reaction with oxygen, nitrogen and hydrogen, which makes their performance reduced. However, during resistance spot welding, under the pressure of electrodes the nugget does not directly contact with the air, so it need not take special protection measures. The rough degree and cleanness of metal sheet surfaces affect the welding quality a lot ${ }^{23}$ ) so it is necessary to reduce the surface resistance by mechanical and chemical methods before welding. In this research, first the sheets were cleaned with hard brush, and then were chemically cleaned by the mixed solution of 45 percent of nitric acid, 20 percent of hydrofluoric acid and 35 percent of water. After etching for 2-3 minutes, the base mental sheets were cleaned with running water.

The spot welding tests were performed using a resistance spot weld machine produced by Miyachi Unitek Corporation. A HF27 high frequency resistance welding power supply 


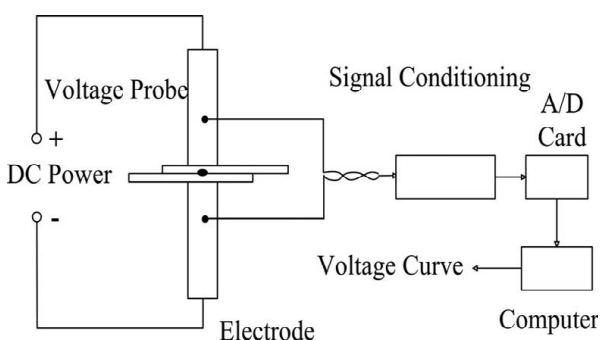

Fig. 2. Schematic diagram of the voltage acquisition system. Implementation of the voltage acquisition system is presented.

Table 2. Chemical compositions of TC2 titanium alloy sheets for SSRSW (mass\%). The table lists the chemical compositions of TC2 titanium alloy which is one kind of titanium alloy brands used in China. All the chemical compositions are in $\mathrm{wt} \%$ form.

\begin{tabular}{|c|c|c|c|c|c|c|c|c|c|}
\hline \multicolumn{3}{|c|}{ Alloying elements } & \multicolumn{7}{|c|}{ Impurities(not more than) } \\
\hline \multirow{2}{*}{$\mathrm{Al}$} & \multirow{2}{*}{$\mathrm{Mn}$} & \multirow{2}{*}{$\mathrm{Ti}$} & \multirow{2}{*}{$\mathrm{Fe}$} & \multirow{2}{*}{$\mathrm{C}$} & \multirow{2}{*}{$\mathrm{N}$} & \multirow{2}{*}{$\mathrm{H}$} & \multirow{2}{*}{$\mathrm{O}$} & \multicolumn{2}{|c|}{ Other Elements } \\
\hline & & & & & & & & Single & Total \\
\hline 4.0 & 1.5 & Remain & 0.30 & 0.10 & 0.05 & 0.012 & 0.15 & 0.10 & 0.40 \\
\hline
\end{tabular}

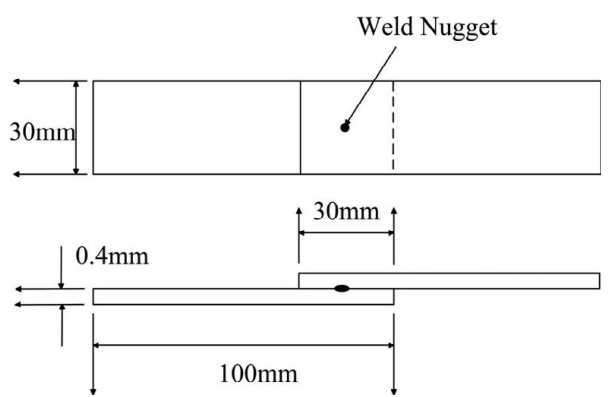

Fig. 3. Dimensions and arrangement of titanium alloy sheets. The titanium alloy sheets were cut in the dimension of $100 \times 30 \times 0.4 \mathrm{~mm}$, installed as lapping joints.

with a pneumatically actuated small-scale resistance weld head was employed in this experiment. The HF27 power supply could provide constant current, constant voltage and constant power modes for a welding process. In this work constant current mode was used, as shown in Fig. 4. The flatted copper alloy electrodes with $3 \mathrm{~mm}$ in diameter were used. No cooling water was supplied to the electrodes.

In order to generate different sizes of nugget, the welding current was varied from 1.0 to $2.4 \mathrm{kA}$, the current time changed from 4 to $12 \mathrm{~ms}$ and the pressure force was varied from 3 to $8 \mathrm{Mpa}$. Nugget diameter was determined from the fractured faying surfaces of tensile-shear testing.

\section{Correlation between Welding Quality and Voltage Waveform}

Figure 5 was the voltage waveform when the welding current was $2 \mathrm{kA}$, the pressure force was $7 \mathrm{Mpa}$ and the welding time was $10 \mathrm{~ms}$. During the initial welding process the voltage increases owing to the rising current and the heating faying surfaces. In the third millisecond the peak point is reached. Due to the constantcurrent, the peak point is the known beta peak. ${ }^{24-26)}$ At this point, the increase in

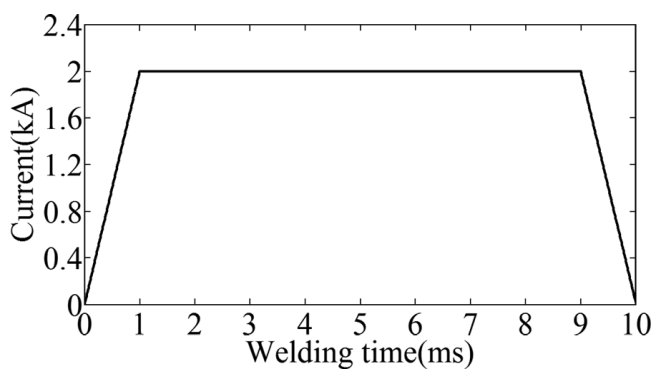

Fig. 4. Constant welding current waveform. Constant current mode was used in this study and the current waveform was shown in this figure.

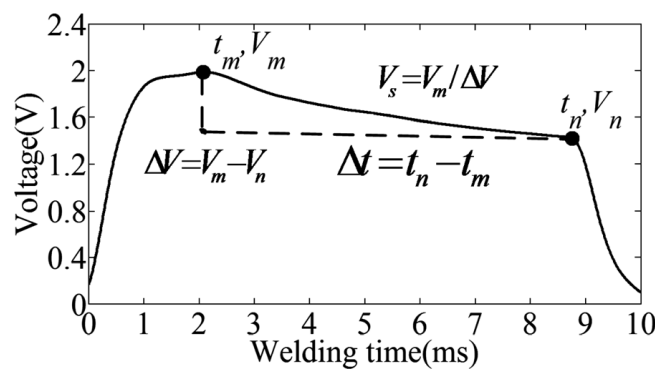

Fig. 5. Voltage waveform and selected features. It shows the voltage waveform when the welding current is $2 \mathrm{kA}$, the electrode force is $7 \mathrm{Mpa}$ and the welding time is $10 \mathrm{~ms}$. These selected features are respectively the time difference between the inflection point and beta peak $\Delta t$ and the corresponding amplitude difference $\Delta V$, the declining rate of the curve $V_{s}$ and the welding heat $Q$.

Table 3. Correlation coefficients between extracted patterns and nugget diameter. The table indicates the correlation coefficients between the extracted pattern and the nugget diameter $D$.

\begin{tabular}{cccccc}
\hline Variables & $\Delta t$ & $\Delta V$ & $V_{s}$ & $Q$ & $D$ \\
\hline Correlation coefficient & 0.7638 & 0.8589 & 0.7030 & 0.9258 & 1 \\
\hline
\end{tabular}

resistivity caused by rising temperature balances with the decreasing resistance due to the increasing size of the molten region and shortening path of the current. After this point the voltage decreases.

Based on the features and the earlier analysis of voltage curve in SSRSW process, four factors were extracted and used for estimation of weld quality in this study. $V_{m}$ was the maximum voltage value, the index $\Delta t=t_{n}-t_{m}$ represented the time difference between the inflection point and beta peak, $\Delta V=V_{m}-V_{n}$ was the corresponding amplitude difference. The selected feature $V_{s}=V_{m} / \Delta V$ represented the declining rate of the curve, which indicated the extent of the nugget growth. $Q=\int_{0}^{t} V(t) d t \bullet I$ was product of the area surrounded by the voltage curve and corresponding current value, which showed the amount of welding zone heat input from the HF resistance welding power supply.

Table 3 is the correlation coefficients between the extracted pattern and the nugget diameter $D$. It could be observed that the welding heat $Q$ had the best linearity with the nugget diameter and the remaining factors exhibited relatively high correlation coefficients of over 0.70 . 


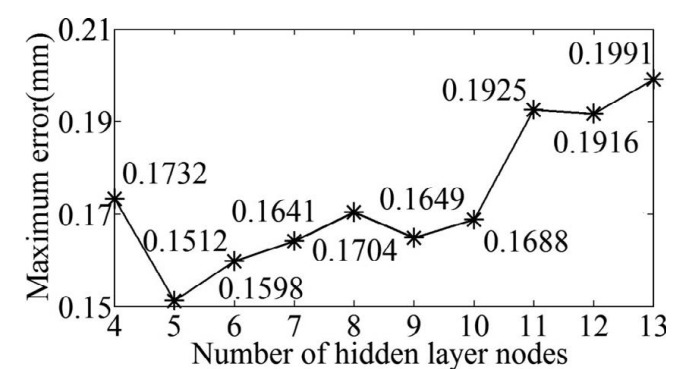

Fig. 6. The average maximum error of different hidden layer nodes on the operation of 100 times. The average maximum error of the neural network model with five hidden layer nodes was about $0.15 \mathrm{~mm}$ to estimate different nugget diameters of small scale resistance spot welding, which is the average value of 100 times and is the least forecast error compared with other hidden layer nodes.

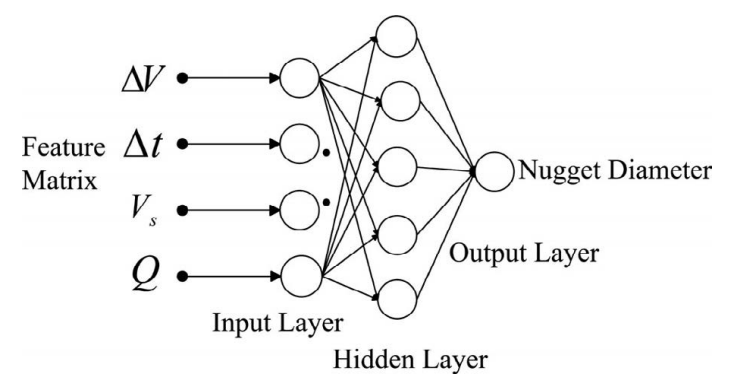

Fig. 7. The ANN architecture. The neural network model is composed of four input layers, five hidden layers and one output layer.

\section{The Neural Network and Quality Inspection}

According to the purpose of the monitoring and the feature matrix, a three layer artificial neural network (ANN) was used to estimate the nugget diameters of the welds. The four estimation indices mentioned above were selected as the input parameters and the nugget diameter was seen as the output layer. The number of neurons to be used in the hidden layer was mainly decided on the basis of output accuracy, computer capability and training speed. Unluckily, there are no fixed rules about the number of nodes which should be used in the hidden layer. If there are too few hidden layer nodes the network may have difficulty in settling the problems that never encountered before. On the other hand, if there are too many nodes in the hidden layer, the network may take an unacceptable time to learn anything of any value. ${ }^{27)}$ Besides, the model with too many hidden layer nodes has a good fit to the sample used for model building but has poor generalization ability for data out of the sample. $^{28-33)}$ So deciding the suitable number of hidden layer nodes is very important and troublesome. In this study, finally five neurons were chosen because it provided a minimum error (about $0.15 \mathrm{~mm}$ ) compared with others, as shown in Fig. 6. So the neural network structure was $4 \times 5 \times 1$ in Fig. 7.

In this study, first 140 pairs of the nugget diameter and corresponding indices were collected and trained in the ANN quality estimation model to decide the weighting and bias values of all neurons. In addition, the learning rate was set as 0.1 , the training goal was 0.00004 and the maximum number of iterations was 1000 . The transfer functions of the

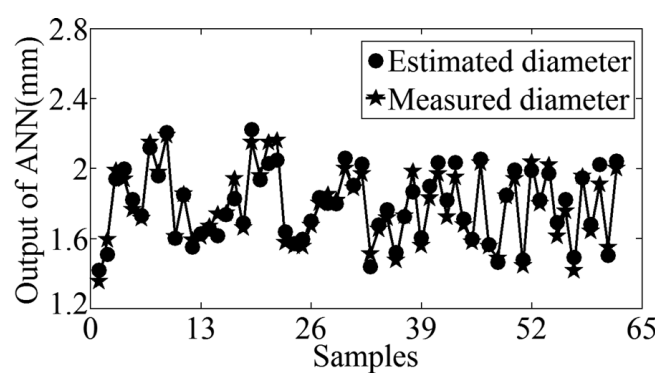

Fig. 8. The estimated nugget diameters by the neural network model. The outputs of ANN are the forecast nugget diameters.

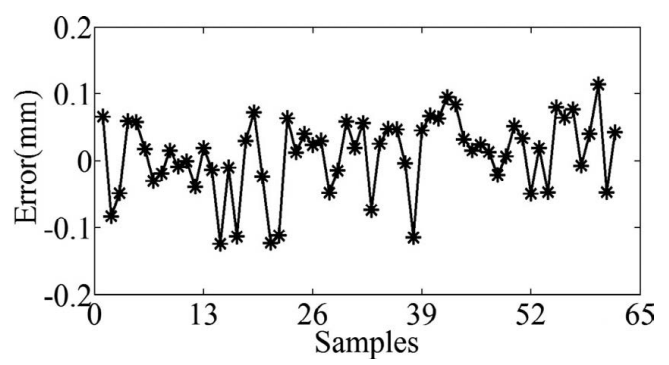

Fig. 9. Error of estimated nugget diameters by the neural network model. The maximum forecast error is about $0.13 \mathrm{~mm}$ proving that using the selected features of voltage curve to estimate the welding quality is an effective way.

hidden layer and the output layer were 'Logsig Function' and 'Purelin Function'. The remained 62 validation data were used to compare the measured diameter with the diameter estimated by the neural network. The results in Figs. 8 and 9 showed that the maximum forecast error was about $0.13 \mathrm{~mm}$ proving that the selected features were so unique that different weld qualities could be perfectly estimated.

\section{Conclusion}

In order to obtain an effective method to monitor weld quality of SSRSW, the voltage curve and the ANN quality estimation model were investigated. Thanks to Miyachi Unitek HF resistance welding power supply and constant current mode provided, a continuous and little error voltage curve could be easily to get. And then four factors were extracted and used as input variables for the ANN. These were the time difference between the inflection point and beta peak $\Delta t$ and the corresponding amplitude difference $\Delta V$, the declining rate of the curve $V_{s}$ and the welding heat $Q$. At last the nugget diameters of the welds were outputted. The maximum average forecast error of the trained network is about $0.15 \mathrm{~mm}$, showing that it performed well. By using this voltage monitoring system and weld quality assurance algorithm, real-time estimation of weld quality could be achieved with only two sensor clips compared with other methods. Furthermore, the probes clipped onto the electrodes did not disturb the welding process in any known way and all the time needed for signal acquisition and processing was short enough to be done before the next welding operation started. In addition, if the current and the thickness were changed, the proposed quality assessment method of SSRSW can still estimate quality of the welding in small error so long as all of the welding work is conducted with 
constant current mode and the power supply provides linear DC or HF current. The only thing we should do is to obtain the new learning data through experiment while the thickness changes. To sum up, the voltage signature could be used as a reliable, in-situ and real-time non-destructive method for monitoring welding quality of SSRSW in a mass production line.

\section{Acknowledgements}

The authors are grateful for the financial supported by the National Natural Science Foundation of China (11072083) and the Chinese Universities Scientific Fund (C2009M002). The authors are also grateful for the experiment supported by the analysis and test centre of Huazhong University of Science and Technology and Dongfeng Peugeot Citroen Automobile Company Limited.

\section{REFERENCES}

1) J. G. Kaiser, G. J. Dunn and T. W. Eagar: Weld. J., 62 (1982), 167s

2) E. P. Patrick, J. R. Auhl and T. S. Sun: SAE Int. Cong. Exposition, SAE, Detroit, Mich, (1984), 14.

3) W. Tan: Small-scale Resistance Spot Welding of Thin Nickel Sheets, University of Waterloo, (2004), 7.

4) J. Chen: Fundamental Studies for Development of Real-time Modelbased Feedback Control with Model Adaptation for Small Scale Resistance Spot Welding, The Ohio State University, OH, (2005), 24.

5) D. Steinmeier: Weld. J., 77 (1998), 39.

6) B. H. Chang, M. V. Li and Y. Zhou: Sci. Technol. Weld. Join., 6 (2001), 273.

7) S. J. Dong, G. P. Kelkar and Y. Zhou: IEEE T. Electron. PA. M., 25 (2002), 355.

8) Y. Zhou, P. Gorman, W. Tan and K. J. Ely: J. Electron. Mater., 29
(2000), 1090.

9) K. J. Ely and Y. Zhou: Sci. Technol. Weld. Join., 6 (2001), 63.

10) S. Fukumoto, K. Fujiwara, S. Toji and A. Yamamoto: Mater. Sci. Eng. A, 492 (2008), 243.

11) W. Tan, Y. Zhou, H. W. Kerr and S. Lawson: J. Phys. D. Appl. Phys., 37 (2004), 1998.

12) T. Adams: Weld. J., 64 (1985), 27.

13) S. I. Rokhlin and L. Adler: Weld. J., 64 (1985), 191

14) E. Waschkies: Weld. World., 39 (1997), 345.

15) K. Tsukada, M. Yoshioka, T. Kiwa and Y. Hirano: NDT\&E Int., 44 (2011), 101

16) W. Tan, Y. Zhou and H. W. Kerr: Metall. Mater. Trans. A, 33 (2002), 2667.

17) C.-S. Chien and E. Kannatey-asibu, Jr.: Weld. J., 81 (2002), 195s.

18) L. Kuscer, I. Polajnar and J. Diaci: Meas. Sci. Technol., 22 (2011), 1.

19) S.-F. Ling, L.-X. Wan, Y.-R. Wong and D.-N. Li: NDT\&E Int., 43 (2010), 200.

20) J. Wen, C. S. Wang, G. C. Xu and X. Q. Zhang: ISIJ Int., 49 (2009), 553.

21) G. R. Archer: Weld. J., 38 (1959), 987.

22) N. T. Williams: Resistance Welding Control and Monitoring, The Welding Institute, Cambridge, (1977), 13.

23) N. Saresh, P. M. Gopalakrishna and J. Mathew: J. Mater. Process. Technol., 192-193 (2007), 83.

24) D. W. Dickinson, J. E. Franklin and A. Stanya: Weld. J., 59 (1980), 170 s.

25) P. H. Thornton, A. R. Krause and R. G. Davies: Weld. J., 75 (1996), 402s.

26) J. G. Kaiser, G. J. Dunn and T. W. Eager: Weld. J., 61 (1982), 167.

27) C. W. Dawson and R. Wilby: Hydrological Sci. J., 43 (1998), 47.

28) H. Yan, W. Liu, X. Liu, H. Kong and C. Lv: Int. Conf. on Computer Application and System Modeling, Taiyuan, China, (2010), V10-635.

29) J. Zheng: Expert Syst. Appl., 36 (2009), 2116.

30) N. Q. Hung, M. S. Babel, S. Weesakul and N. K. Tripathi: Hydrol. Earth Syst. Sci., 13 (2009), 1413.

31) G. P. Zhang: Neurocomputing, 50 (2003), 159.

32) J. Zhou, H. Wang, Y. Yang and J. Ruan: Adv. Intell. Soft Comput., 127 (2012), 433

33) F. H. F. Leung, H. K. Lam, S. H. Ling and P. K. S. Tam: IEEE T. Neural Netw., 14 (2003), 79 